Diánoia, vol. 7, no. 7, 1961

\title{
MEDITACIONES Y ANÁLISIS SOBRE EL ALBEDRIOO
}

1. Lo esencial en mi nuevo modo de enfocar y resolver la cuestión sobre el libre albedrio, y la necesidad de apiortaciones y refinamientos ulteriores para este tema. 2. Variados procesos en el hombre, fuera del libre albedrio. 3. El hombre no es naturaleza. 4. Coincidencias entre la filosofia presente y la ciencia de nuestros dias. 5. La realidad del "yo" y sus decisiones libres. 6. Albedrio y libertad positiva.

1. Lo esencial en mi nuevo modo de enfocar y resolver la cuestión sobre el libre albedrio, y la necesidad de aportaciones y refinamientos ulteriores para este tema.

Desde hace quince años formulé la observación ${ }^{1}$ de que toda la milenaria controversia entre deterministas e indeterministas, en sus variadas modalidades, padecía de un error radical de planteamiento de este tema, error común tanto a los que sostenian que el hombre no tiene libre albedrío, como a los que afirmaban que sí lo tiene. Este error consistía en suponer que el albedrío sea una cosa, energía o facultad que se puede tener o no tener.

El hombre puede tener o no tener determinados miembros de su cuerpo, por ejemplo, brazos - los mancos carecen de ellos_, ciertas aptitudes psíquicas, como la capacidad para hablar idiomas extranjeros o realizar abstrusos cálculos matemáticos, mayor o menor fuerza de voluntad, etc. Ahora bien, el libre albedrío es y significa algo por entero diferente de la posesión de un determinado mecanismo, facultad o resorte - psicológico-, en virtud del cual el hombre pueda actuar libremente. El albedrío es sencillamente la expresión de la situación del sujeto en su circunstancia, es el especial tipo de

1 En la elaboración de esta teoria partí de las premisas contenidas en la metafísica según los principios de la razón vital de José Ortega y Gasset, tal y como éste la empezó a exponer en sus cursos en la Universidad Central de Madrid desdes 1931, la cual fue después resumida en algunas obras suyas posteriores (véase sobre todo: José Ortega y Gasset, Obras completas, Madrid, Revista de Occidente, 1947: II, págs. 228 y sigs., 637 y sigs., 648 y sigs.; III, págs. 324 y sigs.; IV, págs. 164 y sigs., $35^{8}$ y sigs.; V, págs. 21-34, 73-75, 92-121, 174-178; VI, págs. 24 y sigs., 35 y sigs., $41-44,89$ y sigs., $35^{1}$ y sigs., $44^{1}$ y sigs., 479 y sigs.; El Hombre y la Gente (publicación póstuma), Madrid, Revista de Occidente, 1957, págs. 61. 95. Yo presenté la primera exposición escrita de mi concepción sobre el libre albedrío en la segunda edición de mi libro Vida Humana, Sociedad y Derecho: Fundamentos de la Filosofia del Derecho, México, Fondo de Cultura Económica, 1945, págs. 73-92. Esta misma concepción, con nuevos retoques, reajustes y pulimentos está contenida también en mi Tratado General de Filosofia del Derecho, México, Editorial Porrúa, 1959, págs. 83-97. En el presente artículo vuelvo a insistir sobre este tema, porque, conservando lo sustancial de mi tesis más ampliamente desenvuelta en las obras indicadas más arriba en esta nota, resulta que meditaciones ulteriores me han llevado a introducir refinamientos, reajustes, mayores precisiones y aclaraciones $y$, sobre todo, suplementos que me parecen necesarios. 
su inserción en su mundo, que consiste en un hallarse siempre, en cada uno de los sucesivos instantes de su vida, dentro de un margen de holgura determinado, el cual le impone la necesidad de elegir por sí mismo, por su propia cuenta, entre un número, limitado pero plural, de posibilidades, las cuales se hallan determinadas por el contorno concreto que circunscribe al yo. En ese contorno figuran en una gradación de mayor a menor intimidad, o, lo que es lo mismo, de mayor a menor externidad, los componentes ejemplificados a continuación: su propia psique - como juego de mecanismos animicos constitucionales, es decir, aptitudes, capacidades, etc.-; su propio cuerpo - como serie de realidades somáticas, órganos, miembros, etc.-; todo el variadísimo conjunto de las configuraciones, huellas e influencias que lo social ha dejado en su personalidad concreta - lo que ha aprendido de los prójimos presentes y ausentes, vivos y muertos, de estos últimos a través de la transmisión social de la cultura; las actitudes debidas a experiencias, favorables y desfavorables, en el trato con los demás seres humanos; los estímulos y las inhibiciones procedentes de la circunstancia social concreta en que el sujeto esté y viva-; por lo tanto, también todos los ingredientes culturales que han entrado a formar parte de su existencia real, los ingredientes ideológicos, los normativos e institucionales — religiosos, morales, jurídicos, políticos, etc.-, todo lo cual constituye un repertorio con un anverso de facilidades y un reverso de dificultades, con una cantidad de ayudas y con otra cantidad de barreras; los factores de la naturaleza física, en general y en sus concreciones geográficas particulares; las posibilidades y las penurias económicas; en suma, las realidades integrantes de su mundo concreto, individual, mundo que consta en verdad de realidades, de objetos, pero que en cada sujeto, en cada grupo, en cada situación histórica, se forma sólo con una parte de las cosas reales del mundo total - que sólo podemos pensar como correlato de la Conciencia Divina, pero no de ninguna conciencia humana-; y esa porción de cosas, organizada en una singular perspectiva.

Todo ese muy vario y complejo contorno de cada yo, en su singular realidad y forma en cada uno de los momentos de la vida de este yo, condiciona el número y la calidad de posibilidades y potencialidades entre las cuales él tiene que decidirse por si propio; entre las cuales él tiene que escoger para tejer por sí mismo lo que va a hacer, es decir, lo que va a ser su vida en el momento siguiente, o en una serie de momentos sucesivos, incluso en un largo plazo, puesto que cabe tomar decisiones de vigencia prolongada. Claro que esta prolongación no suprime el albedrío, pues - como dice Ortega y Gasseten la vida humana no hay nada que sea inexorable, salvo la muerte, que es el fin de la vida terrenal: cualquier decisión anterior es revocable, y cuando el sujeto no la rectifica en un momento posterior, entonces es que la está ratificando.

El albedrío no es una facultad, no es una energía, no es nada psicológi- 
co: es sencillamente la forzosidad en que el yo está de elegir entre varias posibilidades ante sí, a su alcance, en cada momento, para fabricar el contenido de su vida, en suma, su vida, en el momento siguiente. Cierto que muchos sujetos en verdad no eligen por cuenta propia, antes bien, se dejan llevar por un impulso en su intimidad, o por la corriente dominante en la circunstancia social, $o$, retrayéndose o contrayéndose, dejan que el azar decida por ellos. Pero en esos casos tenemos también una decisión, la decisión de no decidirse, el haber escogido el no escoger por cuenta propia, transfiriendo esta tarea a un factor interno o externo, lo cual en suma es una peculiar manera de elegir, de decidirse, seguramente la manera más pobre, pero al fin y al cabo una de las maneras posibles. Pues entre las varias cosas entre las cuales el sujeto puede elegir en cada momento para ser en su vida en el momento siguiente, una de ellas es no elegir ninguna otra de las posibles y dejarse arrastrar pasivamente por un viento interior o exterior.

Lo que acabo de exponer es el resumen muy concentrado y conciso de algunos de los puntos principales de mi concepción del libre albedrío tal y como la he presentado en publicaciones anteriores.

Pero desde hace algún tiempo me ha venido pareciendo necesario producir algunos reajustes, pulimentos y adiciones complementarias sobre el tema del libre albedrío. $\mathrm{Y}$ esto es lo que parcialmente ofrezco en el presente artículo.

\section{Variados procesos en el hombre, fuera del libre albedrio}

Que el hombre es albedrío no significa que de hecho el conjunto total de cuanto se produce en su vida sea libertad. En el complejo integro de cuanto forma la realidad dinámica de la vida humana, hay muchos y variados procesos que pertenecen a la existencia del hombre sólo en un sentido muy limitado, y que, o son ajenos al libre albedrío, o se han alejado efectivamente mucho de la libertad, quedando conectados con ésta de un modo meramente potencial y remoto. Entre esos procesos figuran: las funciones biológicas de los órganos somáticos; los movimientos puramente reactivos, involuntarios, que responden mecánicamente a estímulos favorables o adversos; lo que el ser humano hace bajo la presión irresistible de una insuperable coacción, fisica o mental. ${ }^{2}$ Pero figuran también, además, aquellas conductas debidas a un proceso de contagio mimético del que el sujeto no es directamente responsable, es decir, que se han producido no por el sujeto antes bien en él, que le han sobrevenido inadvertidamente. Claro que muchas veces el sujeto que esté alerta para eludir o para resistir el contagio mimético podrá sustraerse a éste, y salvarse de tal influencia.

2 Véase: Romano Guardini, Freiheit, Gnarle und Schicksal, Munich, Kösel Verlag, $4^{\text {a }}$ edición, 1956; pág. 18. 
Entre las conductas del hombre que de hecho no se han originado en el libre albedrío o que sólo lejana y débilmente pueden ser referidas a éste, hay que registrar también las acciones que se han mecanizado en forma de hábitos. Claro que en la primera vez, que se produjo el comportamiento que después se convirtió en hábito, hubo una decisión libre, excepto en los casos en los cuales el comienzo se debió a alguno de los mencionados procesos biológicos, o reactivos, o de presión irresistible, o de contagio mimético. Pero, salvo en esos casos mencionados y en otros de tipo similar, los hábitos son adquiridos, y en el momento inicial de éstos hay una decisión libre. Pero cuando el hábito se ha formado ya, entonces opera en varias de sus dimensiones de modo similar a muchas funciones fisiológicas - tales como el respirar, el digerir. La repetición crea un automatismo, unas estructuras mecánicas, las cuales constan, al menos, de dos tipos de ingredientes recíprocamente combinados: por una parte, constan de una configuración orgánica, la cual ciertamente es adquirida, pero que una vez adquirida constituye una realidad bio-psíquica; y, por otra parte, constan también de ingredientes del contorno exterior, los cuales funcionan ora como estímulos, ora como medios, o instru. mentos, o materia. Respecto de lo primero, es decir, del mecanismo biopsíquico hay que recordar que muchos hábitos llegan a integrarse en las zonas más flexibles de los protoplasmas nerviosos de los centros cerebrales superiores. En lo que atañe a lo segundo, los componentes externos, éstos suelen ser de dos clases: materiales y sociales. Como ejemplo de los materiales, pensemos en que no se puede tener ni ejercer el hábito de tocar el piano, si no hay piano, ni el hábito de fumar, si no hay tabaco, etc. En cuanto a los componentes sociales, éstos consisten en estímulos iniciales, en la repetición de tales estímulos que contribuye a formar el hábito y, después, a sostenerlo o alimentarlo; consisten también en los apoyos que otros sujetos dan a un hábito, en forma de aplauso, de admiración, de envidia, de imitación, en suma, en forma de alguna participación positiva, o también negativa, cual una oposición que reafirme el hábito, por vía de réplica. 2bis Son los hábitos, pues, organizaciones de fuerzas biológicas, fuerzas psíquicas, cosas materiales, y factores sociales — cuyo funcionamiento se produce automáticamente. Pero conviene recordar que hay la posibilidad de reformar, e incluso extirpar los hábitos, cuando se cuente con las fuerzas y los medios para ello.

Lo expuesto no comprende todos los procesos que acontecen en el hombre, pero de los cuales éste no es propiamente el sujeto libre. Hay todavía más: hay también procesos debidos a la presión de causas sociales, bien operando éstas por sí solas, bien en combinación con hábitos que ellas mismas han provocado. Voy a analizar primero lo segundo antes que lo primero por razones de ilación. Hay acciones que se han convertido en hábitos por virtud de la presión de una costumbre o uso vigente. Claro que, las más de las veces, en

2błs Véase: Dewey, Human Nature and Conduct, 1922, parte I. 
el momento inicial en que un sujeto se acomoda a una costumbre en vigor, o a otro modo colectivo de conducta vigente, hay una dimensión de libre albedrío; pues, excepto en el caso en que la presión social resultase irresistible el sujeto tuvo que decidir entre adaptar su comportamiento a la costumbre, o sustraerse a ésta, poniéndose en oposición contra ella - en el caso de que tuviera coraje o valentía suficiente para soportar los efectos de su rebelión frente a ella, es decir, para soportar las sanciones sociales por incumplimiento del uso. Puede incluso suceder que aun al repetir una y otra vez, sucesivamente la conducta consuetudinariamente prescrita, el sujeto se plantee el problema de esa conducta, experimente dudas sobre si seguir cumpliendo esa costumbre o tratar de eludirla, o también resistirse contra ella activamente. Pero, en cambio, si adoptada una costumbre, sea por contagio mimético inicial, sea por propia decisión primera, esta forma de conducta consuetudinaria se ha convertido en habitual, en hábito, entonces queda mecanizada, automatizada, y, por ende, sustraída de hecho, actualmente, a la esfera del albedrio. Claro que, en alguna circunstancia bio-psiquica-social, cabe que se dé en latencia la posibilidad de que el sujeto decida un día emanciparse del automatismo que sirve a la costumbre.

El otro tipo de casos aludido antes, es aquel en el que la vigencia de la costumbre es tan vigorosa que, sobre ciertos sujetos apocados, sin mucha energía intima, con escasa fuerza de voluntad, actúa de modo irresistible, como presión inescapable, o como corriente que arrastra de modo incontenible. No se olvide que los usos y costumbres se aparecen al sujeto como la amenaza presente de una eventual violencia, coacción o sanción que los demás van a ejecutar contra el sujeto en el caso en que éste no se amolde a la pauta consuetudinaria. Cierto que para algunos sujetos de ánimo débil esa fuerza del uso obrará como incontrarrestable; mientras que para otros sujetos con un enérgico sentido de su propia individualidad y dotados de recia voluntad, esa fuerza del uso podrá ser superada, en la medida en que estas personas posean los medios psíquicos y sociales suficientes y adecuados para sustraerse al uso -o para emanciparse de él cuando ya lo hubieran observado antes.

Ahora bien, de todo lo dicho - como brevisimo resumen de los resultados obtenidos por la ciencia - se sigue que todos esos procesos bio-somáticos, psiquicos y sociales, pertenecen a la realidad del contorno o circunstancia del yo, y que, por lo tanto, ellos son parte de las condiciones que determinan el ámbito, la cantidad y la calidad de las posibilidades que a cada sujeto se ofrecen en cada momento de su vida. Según la realidad concreta de cada contorno o circunstancia, así será también el número y las características de las posibilidades entre las que el sujeto pueda efectivamente elegir. Nadie puede escoger entre respirar y no respirar -se entiende, esto segundo no más allá de un cortísimo tiempo. Muchas gentes, en un determinado instante, no 
estarán, por inadvertencia, en la posibilidad de sustraerse a un inopinado contagio mimético; o no poseerán, de hecho, las fuerzas necesarias para romper, sin previa preparación, un hábito que los ha avasallado durante largo tiempo. No muchas personas tendrán la suficiente energía interior, convicciones firmes y voluntad suficiente, para escapar a la presión de algunos usos o costumbres. Pues bien, en esos casos hay que constatar simplemente que tales posibilidades de emancipación; al no figurar en el contorno de la persona afectada, no constituyen caminos viables entre los que el sujeto puede efectivamente elegir. Por el contrario, las personas dotadas de las fuerzas biológicas y psíquicas suficientes para vencer algunos mecanismos orgánicos y mentales, o para resistirse a ciertas presiones colectivas, una de las posibilidades entre las que tendrán que elegir será precisamente la de superar esas influencias somáticas, animicas y sociales. Pero hay que observar que probablemente el número de tales personas será casi siempre una exigua minoría.

Que el hombre esencialmente es albedrío no significa, pues, según lo que se acaba de exponer, que todos los procesos que de él emanen o en los que él intervenga, sean actos de libertad; ni significa siquiera que todas las conductas que a primera vista aparecen como suyas se hayan originado en su libre albedrío. A pesar de esto, es decir, a pesar de que muchas acciones del hombre -en número no pequeño - no tienen su origen en una libre elección entre las posibilidades a su alcance, el hombre es libre albedrio. Ciertamente, porque aquellas conductas que no son expresión de libres decisiones no pertenecen al repertorio de las posibilidades reales, de las potencias efectivas que le ofrece la circunstancia. El yo tiene que elegir entre las varias cosas que puede hacer, entre las varias posibilidades que su propio contorno o circunstancia le depara en cada instante; pero, en cambio, no puede elegir aquello que no puede hacer; porque lo que no puede hacer - por defecto bio-psíquico, por interferencia orgánica, por contagio sugestivo o por presión y barrera sociales - todo eso que no puede hacer no figura en el repertorio de las posibilidades entre las cuales tiene que escoger en un determinado momento.

Entonces, en esencia el hombre es libre albedrío. Pero el campo real para ese libre albedrío, el campo real dentro del cual tiene que elegir, es de una amplitud muy diferente en cada sujeto y en cada uno de los instantes de la vida de éste. Así, aunque el hombre es albedrío, siempre y necesariamente en alguna medida, la extensión efectiva del área de libertad en cada individuo, y en cada situación de éste, es diferente; $y$, por grande que sea en un sujeto en cierto momento, en todo caso es limitada, tiene límites.

Por consiguiente, cabe reconocer que cada individuo, en la medida en que se esfuerce en ir enriqueciendo las posibilidades y las potencialidades de su contorno, y especialmente de sus energías bio-psíquicas - sobre todo de su voluntad - y en ir acentuando el intimo sentido de su individualidad, y en la medida en que logre el éxito en tales empeños, aumentará el campo para 
su libre albedrío, conquistará una esfera más grande de libertad. Mientras que algunos hombres parecen autómatas que, sin embargo, disponen de un pequeño ámbito para su albedrío, otros hombres, en cambio, han conquistado una extensa zona para su libertad real.

\section{El hombre no es naturaleza}

En definitiva, el hombre será de hecho tanto más libre cuanto más logre emanciparse de la naturaleza, con lo cual será también más humano en la misma proporción. En este punto se ha producido una coincidencia entre la filosofía más característica de nuestro tiempo y la ciencia de los dos últimos decenios: la coincidencia en reconocer que lo humano propiamente dicho, lo humano esencial, es lo diferente de la naturaleza, de la naturaleza tanto biológica como psicológica, y que, por ende, el hombre es tanto más humano, cuanto más se eleva por encima de la naturaleza y logra dominarla, no sólo de la naturaleza exterior, sino también, y sobre todo de la naturaleza de su propio soma y de sus mecanismos mentales.

Cierto que el hombre tiene naturaleza. Para expresarlo tosca y abreviadamente, tiene cuerpo y alma — uno y otra realidades naturales-; y además vive en la naturaleza (cósmica, física, geográfica, etc.); pero él no es naturaleza. El hombre es quien tiene que vivir con su naturaleza y en la naturaleza; pero su vida propiamente humana no es naturaleza, sino algo muy diferente de ésta, es el argumento que él da a su propia vida, en la medida en que puede y quiere hacerlo; es una obra dinámica de libertad; es la serie de decisiones suyas propias, tomadas por su cuenta y riesgo: es su personal creación. En suma, el hombre es más humano en la medida en que se sustrae a la fatalidad de la naturaleza y a la tirania de la sociedad.

Hay que subrayar que el hombre es más humano en la medida en que se emancipa de la servidumbre social, porque, aunque innegablemente la sociedad consttiuye una urdimbre de fenómenos humanos, de modos especiales de vida humana —modos colectivos_, esos modos colectivos constituyen una mecanización impersonal de lo humano.

\section{Coincidencias entre la filosofia presente y la ciencia de nuestros dias}

Que esencialmente el hombre no es naturaleza, aunque viva con y en la naturaleza, és la verdad filosófica que en nuestro tiempo ha logrado mayor área de reconocimiento, la que parece constituir la doctrina vigente en la época actual. Ahora bien, sucede que las más ilustres avanzadas de las ciencias empíricas sobre los hechos humanos sostienen precisamente lo mismo. $\mathrm{Y}$ en la mayor parte de los casos tales avanzadas científicas han llegado a ese mismo resultado, no por virtud de haber sido influidas directamente por la 
filosofía de nuestro tiempo, antes bien de una manera independiente, por sus propios métodos de investigación. Ni la filosofía aquí mantenida -la cual tiene múltiples concordancias con otras rutas distintas, pero relativamente análogas o paralelas_, ha sido directamente influida en sus origenes por la ciencia contemporánea; ni los científicos que han obtenido resultados concordes estuvieron bajo la acción del nuevo pensamiento filosófico.

Ha pasado ya la época de aquellos cientifismos petulantes que con pintoresca arrogancia querian resolver todos los problemas, incluso los de lo humano, con una simple fórmula de barato materialismo, ora fisicista, ora biologista, ora de otro género similar, y condenaban como vano sueño o puro error toda referencia a otros órdenes de realidad. La ciencia de hoy, por obra de sus más ilustres representantes en el mundo, es mucho más consciente y respetuosa de la superlativa complicación de la realidad: reconoce en ésta zonas muy diferentes, las cuales no pueden ser tratadas por un arbitrario método de caprichosa homogeneización.

Sería muy interesante presentar las muchas concordancias entre la nueva filosofía de la vida humana, por una parte, y, por otra, los enunciados de ciencia empírica obtenidos por los más eminentes psicólogos, antropólogos y sociólogos. Espero presentar ese cuadro en un próximo trabajo. Pero aqui, a continuación, ofreceré algunos ejemplos muy significativos. Sólo unos pocos, pero impresionantes.

Erich Fromm sostiene que el hombre gana tanto más en libertad cuanto más se separa de la primitiva unidad indistinta con la naturaleza y con los demás hombres. ${ }^{3}$ Explica Fromm, además, que el desenvolvimiento del hombre hacia su madurez consiste en un progresivo irse emancipando relativamente de la naturaleza exterior y de su propia naturaleza, y en un progresivo proceso de individuación. ${ }^{4}$ Ahora bien, añade que la existencia humana y la libertad son inseparables desde un principio, en el sentido de ser libre o liberarse de la determinación instintiva. A diferencia de la cadena de acciones instintivas que caracterizan al animal, por el contrario en el hombre la forma de satisfacer sus necesidades permanece abierta, pues él tiene que elegir entre diversos cursos de acción; tiene que valorar diferentes tipos posibles de conducta, tiene que "crear". Al hombre -dice Fromm- le ha tocado un destino trágico: ser parte de la naturaleza y, sin embargo, trascenderla. El acto de desobediencia, como acto de libertad, es el comienzo de la razón. La realidad del hombre no es una realidad natural. Aunque en esa realidad haya ingredientes de naturaleza —anatomia, fisiologia, cualidades psíquicas básicas-, la realidad total del hombre es también y sobre todo su propia obra. Así "como el hombre transforma el mundo que lo rodea, se transforma a si mis-

3 Véase: Erich Fromm, El Miedo a la Libertad, versión castellana de Gino Germani, $4^{\text {a }}$ edición, Buenos Aires, Editorial Paidos, 1958, cap. I.

4 Véase: Erich Fromm, ob. cit. en la nota precedente, cap. II. 
mo en el proceso de la historia. El hombre es su propia creación, por decirlo así. Pero así como puede transformar y modificar los materiales que le rodean sólo de acuerdo con la naturaleza de los mismos, así también puede transformarse a sí mismo sólo de acuerdo con su propia naturaleza". "El hombre, a diferencia del animal, da pruebas de una maleabilidad casi infinita... No hay nada que se parezca a una realidad común a todos los hombres...; y eso significaría que no existe una especie hombre salvo en el sentido fisiológico y anatómico." 5 "El hombre forma parte de la naturaleza, está sujeto a sus leyes físicas y no puede modificarlas, pero trasciende todo el resto de la naturaleza... La existencia humana difiere... de la de todos los demás organismos: se halla en un estado de desequilibrio constante e inevitable. La vida del hombre no puede ser vivida repitiendo el patrón o modelo de su especie: tiene que vivirla él... El hombre es el único animal para quien su propia existencia constituye un problema que tiene que resolver y del cual no puede escapar. No puede regresar al estado pre-humano de armonia con la naturaleza: tiene que seguir desarrollando su razón hasta hacerse dueño de la naturaleza y de sí mismo." 6 "El hombre es el más desvalido de todos los animales, pero precisamente esta debilidad biológica es la base para su fortaleza, la causa principal para el desarrollo de sus cualidades específicamente humanas... El surgimiento de la razón ha creado dentro del hombre una dicotomía, la cual le fuerza a éste a buscar constantemente nuevas soluciones. El dinamismo de su historia es un factor inherente a la existencia de la razón, la cual le lleva a desenvolverse, y, con esto, a crear un mundo propio donde pueda sentirse en su casa consigo mismo y con sus prójimos. Cada etapa que alcanza lo deja descontento y perplejo, y esta perplejidad le urge a moverse hacia nuevas soluciones. No hay una "tendencia hacia el progreso, innata en el hombre; es la contradicción en su existencia lo que le hace proceder en el camino emprendido... Así, el hombre es el eterno migrante o caminante, que está impulsado a ir hacia delante, y a hacer con perdurable esfuerzo que lo desconocido se le convierta en conocido. Tiene que rendir cuentas, ante sí mismo, de sí mismo y del sentido de su existencia". Y, por fin, pongamos punto a estas citas de Fromm, con las últimas palabras de uno de sus libros más importantes: "Ni la conducta buena ni la mala son un resultado automático o predeterminado. La decisión incumbe al hombre. Tal decisión depende de su habilidad en tomarse en serio a sí mismo, en tomar en serio su vida... Depende de su ánimo para ser sí mismo y para sí mismo". ${ }^{7}$

La metafísica según los principios de la razón vital de José Ortega y Gasset, de la cual parte mi concepción sobre el libre albedrio, entiende

5 Véase: Erich Fromm, Psicoanálisis de la Sociedad Contemporánea, $2^{a}$ ed., México, Fondo de Cultura Económica, 1958, cap. II.

6 Véase: Erich Fromm, ob. cit. en la nota 5, cap. III.

7 Véase: Erich Fromm, Man for Himself, an Inquiry into the Psychology of Ethics, Nueva York, Rinehart and Company, Inc., 1947, cap. III. 
que en la relación inicial del yo con su mundo, con su contorno o circunstancia, tal mundo no se le aparece al yo como una realidad que se componga de cosas, o sea de algo que posean un ser en si y por sí. Por el contrario, al yo el mundo se le aparece como un conjunto de facilidades y dificultades, ventajas y desventajas, de instrumentos, utensilios, enseres, medios que sirven - para sus finalidades, aspiraciones, urgencias - o de estorbos, trabas, faltas, limitaciones, privaciones, tropiezos, rémoras, obstáculos; en suma, su mundo consiste en un sistema de importancias, es decir, de algos que importan - positivamente- de asuntos, de pragmata. ${ }^{8}$ Pues bien, con esta caracterización filosófica del contorno o circunstancia del yo, coinciden los resultados científicos de la antropología del profesor inglés S. F. Nadel, quien dice que "los objetos aparecen no sólo como puntos de partida de los procesos mentales, sino como sus puntos finales o metas, de suerte que asumen también por encima de los acentos 'presentacionales', el de una exigencia al yo: la de acatar el estado de cosas, o la de evitarlo, o, en general, la de hacer algo en relación con él. El yo se convierte en el asiento de tensiones y apremios, en punto de partida de movimientos y esfuerzos. .."; ${ }^{9} \mathrm{o}$, dicho con otras palabras, el yo opera en y con los componentes de su contorno, y tomando decisiones entre las posibilidades que esos ingredientse le ofrecen.

El famoso antropólogo norteamericano Ashley Montagu ha llegado a la conclusión de que la característica peculiar que hace del hombre algo único, diferente de todos los demás seres, consiste en que el hombre es libre, está libre, de todas las formas predeterminadas de conducta que condicionan en gran medida el comportamiento de los organismos no-humanos. El hombre no ha nacido teniendo dentro de sí mismo un sistema de respuestas a los estímulos del ambiente. Por el contrario, el hombre ha nacido con un sistema de potencialidades plásticas, que bajo los estímulos del ambiente son capaces de hacer que el sujeto responda en una amplia variedad de diferentes maneras. ${ }^{10}$ EI psicoanalista y sociólogo Otto Rank sostiene que el hecho de que la conducta humana se extienda más allá de la psicología y hacia una concepción más amplia de la personalidad indica que el hombre civilizado actúa no sólo según la guía racional de su intelecto ni tampoco impulsado ciegamente por las fuerzas elementales de sus tendencias. El hombre civilizado emerge por virtud de la operación de un tercer principio, que combina los elementos racionales y los irracionales sobre la base de una concepción de lo sobrenatural. Pero hay más, incluso el hombre primitivo jamás ha vivido sobre una base puramente natural, es decir, sobre una base simplemente

8 Véase: José Ortega y Gasset, El Hombre y la Gente (obra póstuma), Madrid, Revista de Occidente, 1957, págs. 86 y sigs.

9 Véase: S. F. Nadel, Fundamentos de Antropología Social (trad. de F. M. Torner), México, Fondo de Cultura Económica, 1955, págs. 324 y sigs.

10 Véase: Ashley Montagu, The Biosocial Nature of Man, Nueva York, Grove Press, 1956, págs. $4^{2}$ y sigs. 
natural.11 Yo no diré que este aserto sea por entero coincidente con la concepción que yo mantengo, pero desde luego es obvio que, a pesar de las diferencias, estas consideraciones de Otto Rank tienen ecos concordes en alguna medida con la idea del yo como algo distinto y por encima de la naturaleza.

\section{La realidad del "yo" y sus decisiones libres}

Desde luego "yo" no soy ni mi cuerpo ni mi alma. Alma y cuerpo son, por decirlo así, las envolturas más próximas del yo, los componentes del contorno más intimamente ligados al yo. El yo tiene que vivir con su alma concreta y con su cuerpo singular, que son los ingredientes insustituibles, aunque modificables, de la personalidad humana. La psique pasa por muy variados estados de ánimo, por muy diversas experiencias y por importantes transformaciones. Asimismo, el cuerpo padece múltiples modificaciones. Pero el yo es el mismo a través de todas esas vicisitudes somáticas y mentales; es el mismo al que le acontecen todas esas aventuras - y muchas más derivadas del cambio de los otros elementos que integran su circunstancia, elementos del habitáculo físico, del contorno social, del patrimonio cultural, etc. La diferencia esencial entre la psique y el yo _-considerando éste como raíz íntima, profunda y esencial de la personalidad_, fue entrevista ya por los primeros pensadores cristianos, al referirse éstos al fin ético trascendente, reIigioso, del hombre. Si bien emplearon tosca y torpemente la expresión de "salvar el alma", bajo dicho vocablo "alma" no entendían el conjunto de mecanismos psiquicos, antes bien barruntaban algo diferente, a saber: la persona auténtica y entrañable, el "yo" en la acepción genuina y plenaria que tiene el pronombre personal de primera persona en singular. Quien se salve o se condene no será la memoria, la imaginación, el entendimiento y todos los demás mecanismos psiquicos, sino el sujeto, el yo, la persona auténtica. El "yo" es el sujeto genuino, el que piensa y siente, pero no los mecanismos con los cuales piensa y siente; el que sufre y goza, pero no el cuerpo y el alma con que sufre y goza; el que trabaja y crea, pero no los útiles somáticos, mentales y exteriores con los cuales trabaja y crea.

Quizá a algunos les parezca difícil de aprehender esa realidad del yo, que no es corpórea, ni tampoco anímica; pues desde la filosofía griega ha habido la tendencia a pensar en el ser como substancia yacente, e incluso a representárselo como materializado o corporeizado, o, al menos, substancializado. Para que, no ya la concepción del yo, sino simplemente del ser anímico o psíquico como algo incorpóreo, inespacial, aunque real en el tiempo, se abriese camino, se requirió mucho esfuerzo mental. Pero, al fin, llegó un momento en que esa representación de una realidad no corpórea, la anímica, fue ya admitida como algo obvio — con Descartes; y cuando esto se había olvidado

11 Véase: Otto Rank, Beyond Psychology, Nueva York, Dover Publications, 1958, pág. 62. 
o rechazado, se vio claro de nuevo gracias a Bergson. Pero ahora, con respecto al "yo", se trata de pensar éste como una realidad que no es cuerpo ni tampoco alma, como algo que está por detrás o por debajo del alma, y que es real, innegablemente real. Hay mentes, influidas por los sistemas tradicionales de categorias que hallan alguna dificultad en representarse esa realidad del yo, cuando intentan pensarla en una actitud sabia. No obstante, se trata de la realidad más obvia, patente e inmediata, que captamos perfectamente, con sólo estrujar intuitivamente el sentido del pronombre personal "yo". Como dice uno de los personajes de Aldous Huxley - no sólo gran novelista, sino también agudo pensador-_: "yo no soy mi cuerpo, ni mis sensaciones, ni siquiera mi espíritu: soy lo que soy".12 Y es precisamente el "yo" quien decide en cada momento _explícita o tácitamente_ sobre la realidad concreta de la vida, eligiendo una de las varias posibilidades del contorno.

Esa decisión del yo no debe ser confundida con el mecanismo volitivo. La voluntad es una realidad psíquica, más o menos fuerte, un resorte animico, que forma parte de la circunstancia psicológica del sujeto; que forma parte de eso que se ha llamado el "mí", y también la personalidad total concreta de un individuo. Cierto que de las calidades y de la fortaleza de la voluntad de un sujeto depende en parte cuáles sean sus posibilidades efectivas, reales, en un determinado momento; es decir, las características concretas de la voluntad de un sujeto condicionan el ámbito de posibilidades, entre las que el yo tiene que elegir. Ahora bien, el libre albedrio no se atribuye a ningún ingrediente del mi o sea del contorno del yo. Quien es libre es el yo, por virtud del especial tipo de inserción en su contorno, es decir, por virtud de hallarse inserto en éste con alguna holgura, dentro de la cual tiene que elegir decidiéndose por propia cuenta entre las varias posibilidades que su circunstancia le depara en cada momento. El albedrio no es un modo de la voluntad psicológica, sino la especial situación del yo en el mundo, en su mundo, en tanto que tiene que decidirse por sí mismo entre varias posibilidades. Para decidirse por algo, entre lo que puede hacer, el yo emite una especie de "hágase", de un "fiat", de un resolverse a, que pone en acción los mecanismos psíquicos, claro, aquellos de los que disponga concretamente en su propia alma, los cuales a su vez moverán, hasta donde puedan, los mecanismos biológicos.

Reconozco que es muy difícil de exponer, de explicar en qué consista esa extraña realidad que es el yo, cuando éste decide sobre la conducta. Pero si esto es inefable, a pesar de ello tiene una máxima evidencia: constituye algo sentido, visto, intuido de modo directo o inmediato.

Claro que, como se ha indicado ya, la acción libre presupone y maneja materiales, energías, cosas, mecanismos, instrumentos, pero su origen primero lo tiene en el yo, en la decisión de éste.

12 Véase: Aldous Huxley, Eyeless in Gaza, cap. $\mathbf{x}$. 
Así cabe decir de la acción libre que ella no solamente acontece en mí, y se cumple por mi, sino que además procede de mi, esto es, que yo soy su iniciador. ${ }^{13}$

Claro que en este punto hay que diferenciar dos dimensiones. Por una parte, en la acción libre yo soy siempre el iniciador de ella, quien, eligiendo alguna de las posibilidades en el contorno, resuelve o decide hacer lo que hace. Pero eso que hace puede ser una forma de conducta predibujada, en sus líneas principales, en el contorno social, el seguir una especie de sendero trazado de antemano por otros, el navegar por un canal preconstruido. Entonces la decisión del yo, se limita a haber resuelto elegir un camino que estaba ya construido previamente por otros hombres. Pero hay a veces acciones en las cuales no sólo el yo tomó una decisión para llevarlas a cabo, sino que además resolvió disparar las actividades precisas para crear una nueva figura de conducta, para crear un nuevo producto humano. Esta forma de comportamiento creador posee un segundo grado más alto de libertad, porque la tiene no sólo por virtud de la decisión de llevar a cabo una determinada conducta, sino además, en segunda potencia, por convertir la persona en creadora del contenido de su acción. Cierto que esa creación es una de las posibilidades que depara el contorno, pero una posibilidad no preconstituida, antes bien, el resultado de la posibilidad de combinar libremente unas potencialidades no previamente concretadas. Se trata del resultado de haberse decidido a usar libremente unas energías mentales y corporales, unas facilidades sociales, en suma, los materiales, instrumentos y fuerzas que disponga un sujeto. En este caso, la persona no es sólo la que decide, sino que además es autora de su propia conducta, es creadora de esta porción de propia vida. El yo puede delegar el contenido de su decisión en fuerzas o instancias exteriores, esto es, puede decidir no ser él quien construya su propia conducta, sino, por el contrario, aceptar una de las posibilidades preconstituidas en el contorno, aceptar el modelo de una conducta de otro individuo, o aceptar una pauta colectiva vigente, un uso, una costumbre, una corriente de opinión pública, el mandato de una autoridad, etc. $\mathrm{O}$, por el contrario, el yo puede decidir crear por sí propio un comportamiento suyo individual, aunque para ello tenga que utilizar las posibilidades efectivas del contorno, pero aún no concretadas ni predibujadas en ciertos esquemas. La creación humana, genial o modesta, no es creación ex nihilo; por el contrario, es creación valiéndose de materiales, energías, estímulos y productos preexistentes; consiguientemente es creación por virtud de decidirse a aprovechar algunas de las posibilidades del contorno real, construyendo con ellas una nueva forma de conducta, un nuevo producto dimanante de acciones nuevas.

Adviértese muy claramente que los casas comprendidos en el primer

13 Véase: Romano Guardini, Freiheit, Gnade, Schicksal, Munich, Kösel Verlag, $4^{\text {a }}$ ed., 1956, pág. 19 . 
tipo, es decir, la decisión de transferir la decisión a otra instancia, el evadirse de la preocupación de configurar la conducta por propia cuenta, son todavia casos de libertad, porque en ellos hay una decisión que representa haber elegido, entre las varias posibilidades efectivas, una de éstas, que consiste ora en delegar la decisión en otro, ora en dejarse llevar por otros factores de la circunstancia. Por lo tanto, tales casos, aunque lo sean de libertad disminuida, pertenecen a la esfera del libre albedrío, a diferencia de aquellos otros casos -que analicé antes- de imperio inescapable de factores físicos, somáticos, psiquicos o de presión social irresistible.

Reoonozco que puede haber muchas situaciones de carácter fronterizo entre los casos que deben calificarse meramente como de libertad disminuida - decisión libre de delegar la decisión en otro-, por una parte, y, por otra parte, casos de arrastramiento inevitable por factores del contorno (físico, orgánico y social); y claro que en dichos casos liminares el diagnóstico singular de cada uno de ellos puede resultar difícil. Pero, en principio, la distin. ción resulta clara.

Paréceme oportuno mencionar una teoría reciente de Romano Guardini, elaborada por éste partiendo de un enfoque diferente del mío, y que, sin embargo, guarda algún paralelismo con lo que acabo de presentar -en resumen y en complemento de ideas que yo ofrecí hace ya quince años. "El yo capaz de libre albedrío es un yo real. Según la interpretación criticista, por una parte hay la esfera de la realidad, la cual tiene el carácter de la naturaleza, y por consiguiente nada tiene que ver con la libertad, puesto que esa esfera se mueve bajo la forma de la forzosidad; por otra parte, hay la esfera de la libertad, que es algo exigido por la esencia de la moralidad, pero que queda como irreal para el conocimiento intelectivo. El hombre, en tanto que ser real, pertenece a la naturaleza, es un mero individuo bio-psíquico y, en tanto que tal, se halla en una misma línea con la piedra, la planta y el animal. El hombre es un yo, una persona libre en la esfera, no real, de la norma y de la intencionalidad. Ahora bien, esta concepción criticista -dice Guardini- elude el meollo del problema, que se pregunta precisamente cómo se encuentra el yo real, con su libertad real, en el mundo real. Pero el mundo es de tal manera que en él se halla no sólo el substrato material del fenómeno físico-químico, como acontece en el reino de lo inorgánico, no sólo el sujeto soporte de los fenómenos biológicos que se dan en el individuo botánico y en el animal, sino también la persona libre capaz de acción. El yo actúa en la acción libre; pero no surge sólo por primera vez por virtud de dicha acción libre, ni tampoco consiste sólo en ella. Según el actualismo..., la persona existe sólo en la acción libre. Entonces no existiría ningún substrato para la acción, en cuyo ámbito emergería entonces el yo -el mismo absurdo o la misma quimera dentro del área de lo finito, que se da en lo infinito con el Espiritu Absoluto, que se realizaría en el proceso del Uni- 
verso. Ahora bien, lo primero no es la acción, sino el ser, y aquí es la persona real. De esta persona real emana la acción. A quien se atribuye primariamente el carácter de la libertad es a la persona." 14

No considero pertinente entablar aquí una controversia con Guardini, sobre la esencia de la libertad. Para mí, como he dicho, el hombre ni tiene, ni no tiene libre albedrío: el hombre es libre albedrío, por virtud del peculiar tipo de su inserción con holgura en el Universo. Y entiendo que precisa separar hasta el máximo, radicalmente, el libre albedrío, frente a los instrumentos psíquicos y biológicos de los cuales el yo se sirve -especialmente frente a la realidad anímica llamada fuerza de voluntad. No es que censure a Guardini suponiendo que él da dimensión psicológica al libre albedrío. Me inclinaría a entender que no es así. Mas, por otra parte, creo que en las páginas de Guardini no queda suficientemente clara la diferencia entre el libre albedrío y cualquier realidad psicológica; aunque me parece que, desde luego, no recae en el error de atribuir el libre albedrío al alma como una especie de potencia o facultad de ésta. Pero del pensamiento transcrito de Guardini me importa retener y acentuar con singular vigor un punto, a saber: que el yo, la médula de la persona, es real, es una realidad. Se preguntará tal vez: bueno, pero ¿qué clase de realidad? Frente a esta pregunta, por de pronto diré: desde luego no se trata de una realidad corpórea, ni tampoco de una realidad psíquica. $Y$ añadiré, se trata de un tipo de realidad diferente de la realidad material y de la realidad mental. Pero desde luego se trata de una realidad. $\mathrm{Y}$ no hay ninguna razón para considerar que el mundo de la realidad se agota en los sectores mencionados: materia y psique. No hay razón para ello, máxime porque ese tercer tipo de realidad, la del yo, nos es dado como algo inmediato, patente, obvio, con evidencia. Acaso proceda decir con toda humildad, al menos hasta el momento presente, que tal vez el pensamiento filosófico no ha logrado aún apoderarse intelectualmente de modo plenario de tal realidad. Pero, en cambio, la presencia de la misma, presencia directa e inmediata, resulta algo patente, y por lo tanto innegable. Se trata de una experiencia directa, de una vivencia inmediata, el sentirse uno quien singularmente es, el yo individual, incanjeable, singular: la experiencia de la propia mismidad, de la individual identidad.

Esta experiencia de la propia mismidad, de la identidad personal, por debajo y a través de todos los cambios y de todas las variaciones, se da como algo directo, por detrás y al hilo de todas las transformaciones del contorno, del contorno mental, somático, físico, cultural y social, contorno o circunstancia que integra el ser total de la personalidad concreta del individuo. ${ }^{15}$ $\mathrm{Y}$ esa experiencia de la realidad del yo, va acompañada también por

14 Véase: Romano Guardini, ob. cit., págs. 19-20.

15 Sobre la personalidad concreta del individuo, véase: Luis Recaséns Siches, Tratado General de Sociologia, $4^{a}$ ed., México, Editorial Porrúa, 1960, págs. 121-145. 
una experiencia íntima del libre albedrio, como realidad no sólo capaz de decisión, sino además como una realidad que tiene que decidirse por su propia cuenta, sea de un modo activo, sea decidiendo dejar que en su lugar otra instancia decida -el hábito, la costumbre, la opinión pública, el líder, la autoridad, el azar, etc. Claro que en el segundo caso lo que se decide es precisamente eludir la decisión propiamente personal, la decisión individual. Ese segundo tipo de decisión constituye una especie de decisión menguada, de decisión perezosa, de decisión cobarde; pero es, en fin de cuentas, decisión, porque representa haber elegido entre una de las varias posibilidades a la mano: la posibilidad de no preocuparse demasiado por el problema de conducta que la persona tenga ante sí, y delegar la decisión en una instancia extraña al sujeto, externa a él. Y, por ende, sobre el sujeto recae la responsabilidad también de esa decisión por delegación.

Pero hay otro tipo de experiencia íntima, de conciencia inmediata, a través de la cual se hace patente a la vez el libre albedrío y la realidad del yo que decide. A veces el sujeto experimenta el impacto de fuerzas encontradas que están, por así decirlo, luchando entre sí por conquistar su decisión: pasiones, intereses, apetitos, conveniencias, requerimientos de ambición, sentimientos morales, adhesión a unas normas, solicitaciones sociales, etc. El sujeto experimenta que hay factores reales -motivaciones intimas, amores, miedos, concupiscencias, reconocimientos de unas normas, presiones sociales, etcétera - cada uno de los cuales está tirando de él para arrastrarlo en su dirección. Incluso hay momentos en que el sujeto se sentiría inclinado ante la lucha que se libra dentro de sí mismo a aventurarse a predecir, suponer lo que va a pasar, basándose en una calibración de los respectivos factores operando dentro de su personalidad concreta, algunos provenientes del exterior y otros enraizados en su propia intimidad. Algo así como si el sujeto tratara de objetivarse a sí propio y verse como hoja impelida por vientos contrarios; $y$, entonces, midiendo las respectivas fuerzas de los diversos vientos, tratara de calcular qué derrotero vaya a ser el resultado, tratara de predecir, por virtud de una apreciación de probabilidades. Claro que el sujeto, según expuse ya, puede decidir no escoger y dejarse sencillamente dominar por la motivación más fuerte. Pero también, si la circunstancia integral -que lo compone y en la que está- se lo permite, puede levantarse por encima de esa lucha entre motivaciones varias, erguirse como señor de la situación, como juez sobre las partes en disputa, y, utilizando y aprovechando las fuerzas psíquicas y somáticas de que efectivamente disponga como posibilidades reales en su circunstancia, decidir por sí mismo, en un plano más alto que el choque de las motivaciones, y por encima de ellas, se entiende por encima también y principalmente de la motivación más fuerte. Entonces el yo tiene la expe. riencia de que es libre, claro que sólo dentro del marco de las posibilidades que su contorno le depara en cierto momento. 
Asi pues, el hombre es siempre libre albedrío; porque tiene que decidirse, quiéralo o no, por alguna de las posibilidades que la circunstancia le ofrece. Pero sucede que en muchas ocasiones decide no decidirse activamente por sí propio, decide traspasar su decisión a otro, a otro individuo o a otra realidad, al azar, o a la sociedad. Entonces también hay decisión, decisión del yo; pero lo que hay no es una decisión que incluya o requiera una actividad propia, sino la decisión de someterse pasivamente a fuerzas extrañas. En cambio, cuando el yo se ha elevado por encima de las fuerzas en conflicto y ha cobrado conciencia de que en definitiva es albedrío y puede elegir por si y ante sí, libremente, una de las posibilidades efectivas de que dispone, sin tener que plegarse a una mecánica de fuerzas, entonces actualiza auténticamente su libertad. Entonces el sujeto tiene la experiencia de que está actualizando de veras su libertad, de que no ha ejercido esa libertad precisamente para renunciar de facto a la misma, antes bien, de que la ha practicado, de que ha aprovechado su capacidad y su necesidad de decisión, de elección, para elegir una actividad libre, para escoger una conducta propiamente suya.

Esta distinción permite diferenciar en la realidad entre conductas propias y auténticamente libres, por una parte, y, por otra parte, conductas que implican lo que podríamos llamar decidirse por renunciar a una elección activa, personal, individual. $\mathrm{Y}$, claro es que entre esos dos tipos extremos de conducta se da una variada gama de casos intermedios. El tipo extremo de libertad actualizada sería la acción individual creadora, la invención individual -en moral, filosofía, ciencia, técnica, política, trato interhumano, etcétera- contra los vientos y las mareas que pudieran interferirla o estorbarla, superando los obstáculos o dificultades. Dentro del tipo opuesto podríamos colocar los siguientes modos de conducta y otros similares: decidirse por el conformismo o pautas ajenas, colectivas, o de un líder; también otras decisiones que implican un querer evadirse de responsabilidades personales, por ejemplo, resolviendo hacer lo que supone que ha de agradar a otras personas: también la decisión de no luchar activamente contra fuerzas internas, dejándose avasallar por éstas, hasta el punto de convertir en hábito tal sometimiento; etcétera.

Estos dos tipos extremos, desde el ángulo de la descripción empírica, en términos de generalización, vendrian a coincidir con lo que Erich Fromm llama, respectivamente: libertad positiva, en el primer caso descrito; y evasión de la libertad, en los casos opuestos.

En el segundo tipo suele suceder que el yo auténtico queda soterrado y poco activo bajo un conjunto de excrecencias, de configuraciones producidas y añadidas por factores internos -azoramiento, miedo, compulsiones neuróticas-, y por factores externos -autoritarismo, masificación gregaria y animalizante, etc.; $y$ entonces esas excrecencias y esas configuraciones 
vienen a constituir una especie de pseudo-yo que oculta y que paraliza -relativamente-, la realidad del yo auténtico, y que angosta el ámbito de las posibilidades efectivas para la conducta de esa persona, que sufre la sustitución parcial de su yo genuino por ese pseudo-yo. ${ }^{16}$

En cambio, en el primer tipo se da la experiencia de libertad como iniciativa, como decisión inicial, como creación, como responsabilidad, no sólo de la elección, sino también del contenido de la elección. En este caso, el sujeto se siente responsable, diríamos metafóricamente, con la médula de su propio ser, con la raíz de su propia persona, en suma, con su propio yo. El sujeto se siente como tripulante de un vehículo que él mismo maneja y cuya ruta viajera la decide él mismo, a diferencia de lo que sucede en el segundo tipo, en el cual el sujeto se deja llevar apoltronado en el asiento de un vehículo que es manejado por otro, o que corre a la deriva impulsado por fuerzas externas como el viento. Cabe que dicho sujeto apoltronado dispusiera de la posibilidad de apearse del vehículo, para después meditar y decidir por su propia cuenta un lugar a donde ir; o de la posibilidad de hacerse él mismo con el mando del vehículo. Claro que en cualquiera de esos ejemplos el conductor del vehículo no puede hacer cualquier cosa que se le ocurra: por el contrario, está limitado por los factores de la naturaleza física -obstáculos en el camino, en el agua o en el aire-, por los dispositivos del artefacto técnico que maneja, por su capacidad de resistencia bio-psíquica para su acción de pilotaje -es decir, tolerancia para la fatiga-; etc. Pero dentro de los límites impuestos por esos variados factores, el conductor que se decidió a actuar por su cuenta individual puede ir elaborando su propia ruta. En cambio, el pasajero apoltronado, o el perezoso, o el que tuvo miedo a tomar resoluciones por su cuenta, el que tuvo miedo a responsabilidades individuales, decidió dejarse llevar por otro, o por otros, o por las fuerzas del azar.

Claro que en uno y otro caso hay responsabilidad. Pero en el segundo la responsabilidad consiste en haber decidido no ser responsable. Cierto que se es responsable de esa decisión de no haber querido ser responsable, e indirectamente se es responsable de las consecuencias. Pero no se es directa e inmediatamente responsable del contenido de una acción o de una omisión; es decir, se es responsable en todo caso, pero no se es autor personal de la conducta positiva o negativa. Por el contrario, en el caso de una conducta auténticamente personal, genuinamente propia, efecto de una decisión activa, la responsabilidad cobra su grado máximo, y con éste su plenitud de sentido. "Ser responsable" quiere decir que uno es preguntado y debe contestar, y además que esa contestación implica una decisión del propio yo. Ahora bien, en el segundo caso, es decir, en el que el sujeto resolvió dejarse llevar por otros factores, la decisión del yo, implicada en la responsabilidad, se contrae al hecho de haber resuelto no resolver por sí mismo. En el primer caso, en el

16 Véase: Erich Fromm, El Miedo a la Libertad, cap. v. 
cual el yo resolvió decidir por sí mismo una forma personal de conducta, la decisión del yo implicada en la responsabilidad extiende ésta al contenido de la acción. La libre decisión por cuenta propia, es decir, cuando el yo carga sobre sí toda la responsabilidad de su conducta, cuando el yo no simplemente se resuelve por una de las posibilidades que tiene ante sí, sino que la posibilidad que elige le impone tener que actuar por si mismo, construyendo por así decirlo su acción, puede ser el mejor camino para la autenticidad, y, consecuentemente, el mejor camino para la realización positiva de la moral -pues quizá el imperativo moral positivo, a diferencia de las prohibiciones, las cuales son sin duda muy importantes, sea el de buscar y reali. zar el verdadero proyecto de vida, la genuina vocación que es cada persona individual.

Esa libre decisión plenamente responsable puede ser el mejor camino para el cumplimiento de la misión moral que cada individuo lleva implicada en su personalidad concreta; ${ }^{1 \tau}$ pero con esto no se dice que tenga que serlo necesariamente. Cabe que el yo pronuncie decisiones con total responsabilidad las cuales le lleven precisamente a la deserción de esa vocación, o que le lleven a una conducta inmoral. No todos los artífices de su propia conducta son necesariamente buenos; puede haber y hay entre ellos grandes malvados, talentosos arquitectos de la inmoralidad.

Ni que decir tiene que entre los tipos que he señalado se da en la realidad de la conducta una variada gama de casos intermedios. Entre el tipó de la decisión plenamente responsable, responsable no sólo formalmente por lo que atañe al haberse decidido por una de las posibilidades, sino además profundamente responsable del contenido de la conducta elegida, contenido construido o elaborado por la persona misma, por una parte, y por otra parte los procesos orgánicos, los hábitos y las presiones sociales irresistibles que operan en un ser humano - progresos que están fuera del albedrio-, hay un escalonamiento de grados intermedios. Hay casos liminares con los tipos de procesos humanos de carácter fisiológico, de contagio mimético, de sugestión, de automatismo bio-psíquico, o de coerción social o contrarrestable; casos que no son puramente y de modo total ninguno de esos tipos mencionados, pero que están muy próximos a alguno de ellos; y entonces tales casos se dan en una especie de zona claro-oscura, más oscura que clara, en la que tal vez la elección libre tiene un campo muy pequeño, muy pobre, de posibilidades. Claro que en la medida en que hay elección entre varias posibilidades, por pocas y pobres que éstas sean, hay libre albedrío, pero apenas hay nada de acción personal creadora. Esto es lo que pasa con la persona cuya vida discurre por los caminos preconstituidos del uso y la costumbre, de la

17 Véase: sobre el proyecto de vida y la vocación concreta de cada persona: Luis Recaséns Siches, Tratado General de Filosofia del Derecho, México, Editorial Porrúa, 1959, págs. 246-259. 
persona cuya existencia corre a lomo de modos colectivos, por carriles sociales genéricos y comunales. Hay en tal caso albedrío, en tanto en cuanto esta persona tuvo que elegir entre diversas vías colectivas, entre varias costumbres todas ellas con alguna vigencia; o en tanto en cuanto eligió acomodarse a alguno de esos canales colectivos en vez de esforzarse en hallar su propio camino personal. En esos casos hay albedrío, pero la elección realizada en función de éste representa haber escogido la posibilidad más pobre, más gris, más impersonal, menos creadora: el haber escogido la línea más fácil - pero la más apagada, la menos fecunda, la menos personal, la que está más cerca del gregarismo animal.

Adviértase, sin embargo, que el hecho de haber elegido en ciertos casos, entre las posibilidades dadas, la línea colectiva, la costumbre en vigor, no significa siempre y necesariamente lo que he descrito en el párrafo precedente, es decir, no significa forzosamente una línea baja del menor esfuerzo, una renuncia a la posibilidad de aspirar a una realización propiamente personal. Puede constituir eso; y de hecho eso es lo que representa en muchísimos casos. Pero puede significar algo distinto y además contrario: el haber elegido la ruta comunal, y haber hecho a un lado, con doloroso sacrificio, con gran esfuerzo y hasta heroísmo, una aspiración personal, por considerar eso en tal caso como el cumplimiento de un imperativo ético, de decoro externo, de sumisión al bien común, de conservación del orden y de la paz, de exigencia de justicia, de respeto al prójimo, de automortificación, de reserva de las propias energías y de las cosas disponibles en el contorno para la realización de empresas de otro orden. En tales casos, el elegir el sendero colectivo, el someterse a la costumbre vigente, significa no lo fácil, antes bien la línea más difícil. Esto sucede cuando un hombre con vivísima conciencia de una vocación individual, con un profundo sentimiento de una misión personal, decide sacrificar algún aspecto de la realización de ese proyecto singular, al imperativo ético de la paz y el orden sociales, del bienestar de sus semejantes, de servicio a su familia, a su nación. En tales casos elegir la ruta de someterse a presiones colectivas representa elegir una posibilidad que no es fácil, antes bien difícil, porque la puesta en práctica de esa línea comunal requiere un muy penoso sacrificio de fuertes aspiraciones personales.

El tipo de elección que consiste en escoger una conducta plenamente personal, íntegramente responsable, auténticamente creadora, constituye más bien un caso límite que es muy poco probable, que es casi imposible, hallar en la realidad. Porque el inventor más genial, el creador más original -en moral, política, filosofía, ciencia, técnica, arte, etc. - no tiene la posibilidad de proyectar su persona en el vacio; antes bien, por el contrario, tiene que operar con el alma singular concreta que le ha tocado en suerte, con el repertorio de potencialidades biológicas de su cuerpo, con las cosas de su contorno material, con las capacidades que ha adquirido por educación, con 
las facilidades o contra las dificultades que halle en sus prójimos, en suma, con los componentes de su circunstancia. Entonces lo que sucede es que un tipo humano tal opera y crea dentro de su contorno y con los componentes de ese contorno, entre los cuales figuran modos de conducta aprendidos de la sociedad, incitaciones recibidas de otras personas, formas mentales asimiladas de la cultura circundante; por ende, entre los cuales figura un variado conjunto de ingredientes no individuales.

\section{Albedrio y libertad positiva}

Ciertamente todo ser humano es albedrío. Lo es no sólo la persona de alta jerarquía en la moral y en otras ramas de la cultura; sino que lo es también el más desventurado de los seres humanos que esté escaso de dotes mentales, que sufra las limitaciones de su cuerpo enfermo o tullido, que no haya recibido apenas beneficios de educación y cultura, que carezca de medios económicos, en situación de miseria; porque incluso un tipo tal de hombre tiene que elegir entre varias posibilidades. Esas posibilidades serán pocas y pobres; pero como hay más de una, tiene que elegir. Las posibilidades son siempre varias, por lo menos serían dos. Pues si alguien supusiera que pudiese darse el caso de que hubiera una sola posibilidad, un sólo camino tenebroso, ciertamente no habría únicamente una sola posibilidad o vía, sino que habría dos: la de aceptar aquella única ruta, o la de evadirse de la existencia. Desde luego condeno el suicidio desde el punto de vista ético - moral y jurídico. Pero lo menciono como caso límite, para poner en evidencia que en cualquier momento de una existencia humana, habría más de una posibilidad, habría por lo menos dos.

Es albedrío también el ser humano que haya sido en gran parte deshumanizado, por causa de fuertísimas presiones colectivas, como las que imperan en el monstruoso Estado totalitario - de cualquier tipo que éste sea: soviético, fascista, nazi o similares. Incluso en tales casos, el ser humano sometido a tan terribles y estranguladoras presiones, afronta el tener que elegir entre varias posibilidades. El Estado totalitario es sin duda un aplastador mecanismo que quiere someter no sólo el cuerpo sino también el alma de sus súbditos; es un artefacto pavoroso para desindividualizar, esto es, para deshumanizar a la gente. Pero por terrible que esa tiranía resulte, de hecho no puede conseguir sus propósitos en un cien por ciento, $y$, por estrechas y apretadas que sean sus mallas, siempre quedan algunas zonas de franquía entre cuyas posibilidades _ aunque pocas — tiene el sujeto que elegir. Y por mucho que el Estado totalitario logre despersonalizar al sujeto, en éste sigue existiendo, aunque oprimida, la raíz de su persona.

Ahora bien, todo lo dicho muestra que se debe distinguir entre la esencialidad de albedrío que cualquier hombre es, y el grado de libertad positiva, 
realizada, efectiva, que ha logrado conseguir. En lo segundo hay una escala de grados muy diversos: desde los tipos débiles, desvalidos, pobres, y los tipos oprimidos, hasta los tipos que han conseguido grandes realizaciones personales.

Ser albedrio expresa el peculiar modo de inserción del yo en su contorno, inserción con un ámbito de holgura dentro del cual el yo tiene que decidirse eligiendo alguna de las posibilidades que esa circunstancia le presenta, ora posibilidades previamente delineadas - como son las de los modos colectivos-, ora posibilidades a manera de potencialidades con las cuales la persona construye su propio camino. Y ser albedrio implica que el yo constituye una realidad capaz de proyectar fenoménicamente nuevas causas en el mundo de los hechos naturales - físicos y psíquicos-, las cuales vienen a unirse y combinarse con las causas preexistentes; es decir, la capacidad del yo para proyectar un plus de causalidad en el mundo determinado de la naturaleza; la capacidad de actuar, no precisamente suspendiendo el proceso causal de los hechos psíquicos, biológicos y físicos, antes bien, por el contrario irrumpiendo en ese proceso mediante la proyección de nuevas causas en la forma de cualquier otro fenómeno. En suma: actuando por virtud de la creación de nuevas causas, al modo como esto ha sido concebido y descrito por Kant y por Nicolai Hartmann.18 Sólo que hay que insistir en que, para eso, es preciso que reconozcamos que el yo constituye una realidad activa, bien que se trate de una realidad diferente de la psíquica y diferente de la somática. La decisión del yo, colocándose por encima de las tendencias en lucha en su alma, y empleando las fuerzas de que disponga -que pueden ser mayores o menores según el individuo concreto de que se trate, y según el momento singular de su vida-, constituye una especie de acto creador, un querer, no psíquico sino prepsíquico, algo así como un fiat, viene a constituir una especie de origen relativo, de comienzo relativo de un proceso de conducta. Digo que es un origen, un comienzo, un principio, porque el yo experimenta que con su decisión está iniciando un proceso de acción. Digo que ese origen o comienzo es relativo, porque el inicio se inserta creadoramente, modificadoramente, en un proceso ya en curso, con antecedentes. Claro que esta caracterización se'aplica a los casos en que el yo decide resolverse por su propia cuenta; y no a los casos en que decide no decidirse y dejarse llevar por una corriente, esto es, cuando la posibilidad que elige es de aceptar una presión o una solicitación, lo cual constituye una de las posibilidades efectivas de la circunstancia.

Cuando el yo, se decide como auténtico señor sobre las solicitaciones de estímulos externos o internos, poniendo al servicio de su decisión los componentes de su contorno anímico, somático, y exterior, entonces podemos hablar de libertad positiva, de conquista real de la libertad. Algunos entienden que

18 Véase: Nicolai Hartmann, Ethik, 1926, última parte. 
esto se da solamente cuando la posibilidad elegida por el yo está de acuerdo con inspiraciones éticas -morales, de justicia, o de decoro. Pero me parece que esta consideración no es correcta, aunque esté inspirada en un punto de vista que indiscutiblemente merece alta estimación. Ciertamente que el sentido de libre albedrío radicará en el cumplimiento de la misión ética de la persona, en su autosalvación, en su realización auténtica según inspiraciones morales. Y digo "inspiraciones", porque este término es más amplio que el de "normas". Las inspiraciones contienen las normas, pero son algo más extenso que éstas, porque abarcan no sólo las normas estrictas - la mayor parte de ellas negativas - , sino además también las directrices para realizar la misión positiva auténtica de la persona individual, aquello que constituye el sentido de la unicidad individual de cada ser humano. Es verdad que sólo al servicio de las inspiraciones éticas - entre las cuales figura la fidelidad a la propia vocación auténtica - la libertad positiva cobra su plenitud de sentido, que es un sentido axiológico. Pero no sólo en ese caso existe realmente libertad positiva, genuinamente creadora. Esa libertad positiva puede darse también en personas que han logrado actuar señorialmente sobre su mundo, que han sabido sacar un gran partido en aprovechamiento de las posibilidades de su contorno, dando a su conducta dimensiones creadoras, aunque esa conducta pueda ser justificadamente objetada desde un punto de vista ético. Claro que reconocer esto no impide que, por otra parte, se comprenda que la libertad tiene esencialmente un sentido ético, con lo cual se entiende que pertenece a la esencia de la libertad el deber constituir un medio precisamente para la realización de los valores y entre todos ellos, y en la cúspide de ellos, para el cumplimiento de los valores morales.

Luis Rrcaséns Siches 